\title{
Future developments in health care performance management
}

\author{
This article was published in the following Dove Press journal: \\ Journal of Multidisciplinary Healthcare \\ 12 November 2013 \\ Number of times this article has been viewed
}

\section{Maria Crema \\ Chiara Verbano}

Department of Management and Engineering, University of Padova, Vicenza, Italy
Correspondence: Chiara Verbano Department of Management and Engineering, University of Padova, Stradella San Nicola 3, 36I 00 Vicenza, Italy Tel +390444998731

Fax +3904 44998888

Email chiara.verbano@unipd.it
Abstract: This paper highlights the challenges of performance management in health care, wherein multiple different objectives have to be pursued. The literature suggests starting with quality performance, following the sand cone theory, but considering a multidimensional concept of health care quality. Moreover, new managerial approaches coming from an industrial context and adapted to health care, such as lean management and risk management, can contribute to improving quality performance. Therefore, the opportunity to analyze them arises from studying their overlaps and links in order to identify possible synergies and to investigate the opportunity to develop an integrated methodology enabling improved performance.

Keywords: health care, lean management, clinical risk management, quality, health care processes

\section{Introduction}

The pressure to "review spending" as a result of reduced public resources is affecting public health care costs, which have to be reduced by eliminating waste ${ }^{1}$ while considering the level of quality at the same time. In addition to considering patients' increasing awareness of health care and the growth of organizations in defense of patients, standards of quality must be guaranteed for the accreditation process, which can follow four different models, ie, "visitatie", International Organization for Standardization, European Foundation for Quality Management, and organizational accreditation, or the Joint Commission International program, which combines the strengths of all of these models into a common health care quality evaluation. ${ }^{2}$ Moreover, achievement of a high level of quality in health care is pressed for by national and international organizations, ${ }^{3-5}$ as well as by ethical and social concerns. All the aspects mentioned above complicate the health care system, which indeed is complex in itself. As a service business, it is characterized by intangibility, heterogeneity, and inseparability of production and consumption. ${ }^{6}$ These critical elements of any service company affect the degree of process standardization, marketing and communication polices, employees' roles, management capacity, and mechanisms of quality control and performance evaluation. ${ }^{7}$ In addition to having these special features, health care companies also provide a unique and critical service, considering the particular condition (both physical and psychologic) of their customers. ${ }^{8}$ 
Shortell and Kaluzny ${ }^{9}$ have individualized other peculiarities of health care companies:

- high variability and complexity of the work, given that the nature of a substantial part of it is considered urgent and must not be delayed; the work involves a high degree of specialization and has a limited tolerance of error

- work activities are highly interdependent, requiring a high level of coordination between different professional groups

- people, who play a relevant role in the organization, are highly professional and loyal to their professional category rather than to the organization they work for

- there is little organizational or managerial control on medical staff, which strongly influences the effectiveness and efficiency of health care service.

The central element around which all the activity carried out by the health care organization revolves is the human relationships developed between the patient and health care staff. Therefore, the centrality of people (and not the exchange operation, as traditionally occurs in economic studies) is what best represents the distinctiveness of these companies. ${ }^{10}$ According to Serpelloni and Simeoni, ${ }^{11}$ the general objective of a health care organization is to protect and promote citizens' health with the highest technical quality and providing customer satisfaction at the lowest cost.

This paper discusses how it is possible to pursue these different performance objectives, considering different points of view and highlighting the potential of new approaches that could enable health care organizations to successfully manage their performance, especially if adopted in a synergistic way. The paper is organized as follows: management of performance in health care is presented considering different theories in the second section; recent managerial approaches supporting performance management are discussed in the third section; and opportunities for future research emerging from the previous discussion are developed in the final section.

\section{Management of performance in health care}

The issue of pursuing different performance objectives, as developed from the definition of Serpelloni and Simeoni ${ }^{11}$ in the health care context, is not new; Skinners ${ }^{12}$ and Hayes and Wheelwright ${ }^{13}$ highlighted the need to choose the performance objective on which to focus at the expense of others. This approach has been discussed in the literature by several authors, who have underlined its limitations but also noted its potential, comparing it with the so-called "cumulative" models and with the theory of performance frontiers and performance improvement. ${ }^{14-20}$

In particular, many of these theories try to provide a sequence for pursuing different performance objectives. Perhaps the most famous of these is the theory of the sand cone of industrial origin, ${ }^{21}$ which recognizes quality as the primary target on which to focus before developing strategies aimed at improving flexibility and delivery, obtaining finally, as a causal effect, a reduction in costs. This means that there is an optimal sequence for achieving improvement in performance, following a cumulative process. In order to obtain stable improvement, first a minimum level of quality should be reached; only afterwards can the firm consider aspects of reliability. To increase the levels of quality and reliability, the next step is to improve the speed of internal processes; the flexibility of the response will be the most effective way to do this, coherently changing the organizational structure. Only after achieving a minimum level for this performance should firms consider efficiency.

The authors suggest that, by focusing on quality first, organizational abilities are nurtured more, thereby emphasizing cost efficiency objectives. Most companies that have developed quality improvement programs also report lower costs. Takala et $\mathrm{al}^{22}$ observed that all the layers of the cone are supported by the quality of the processes; cost efficiency is at the top of the cone as the ultimate goal, with only a small influence on the structural stability of the cone itself. In the study reported by Takala et al, ${ }^{22}$ the sand cone is adapted with the aim of highlighting the successful strategies that an airline company has to pursue to succeed; flight safety is placed among the basic pillars, along with high quality of personnel, know-how, and work environment and technology.

Turning to the health care context, quality plays a fundamental role, as argued before, and patient safety could constitute one of the basic pillars. Therefore, the definition of quality in health care seems to be a critical issue. Although the theory of the sand cone should be adapted to the context $\mathrm{t}^{21}$ and to the strategies identified, quality seems to be the starting point according to many studies. ${ }^{14,15}$ Therefore, quality in health care needs to be defined. Because health care is a service industry, we could refer to the literature, in which quality of service has been defined as a measure of the match between quality of performance and customer expectations. ${ }^{6,23}$

The distinction between customer satisfaction and quality of service has been studied by several authors, leading to the definition of Bitner and Hubbert:24 "the consumer's 
overall impression of the relative inferiority/superiority of the organization and its services." Some studies have translated these concepts into health care, despite difficulties of implementation, ${ }^{25,26}$ where some authors describe quality as the extent to which the desired health outcomes or "expectations" of patient services are met. ${ }^{27,28}$ However, considering that the right to health care is universally recognized and protected, ${ }^{29,30}$ quality in health care should go beyond patient expectations and satisfaction. According to the Agency for Healthcare Research and Quality, ${ }^{31}$ quality is doing the right thing, at the right time, in the right way, for the right person, and achieving the best possible results. In line with Buttell et al, ${ }^{32}$ quality of care should increase the likelihood of desired health outcomes, being consistent with current professional knowledge (professional practitioner skill) and matching the expectations of health care users (marketplace).

Adopting a meaning of quality of service that Holbrook and Corfman ${ }^{33}$ would define as more mechanistic (involving an objective aspect or feature of a thing or event) than humanistic (involving the subjective response of people to objects and therefore a highly relativistic perspective), quality should also take account of other aspects, such as patient safety and error reduction. These latter issues should be considered a subset of a larger, more complex, and multidimensional concept of quality of care.

Considering the definition used by the World Health Organization, ${ }^{34}$ a health system should be considered as being of a high level if it is effective, efficient, accessible, acceptable, patient-centered, equitable, and safe. These are the same characteristics recognized by the Agency for Healthcare Research and Quality ${ }^{35}$ and reported by the Institute of Medicine ${ }^{36}$ for health care service of high quality, ie, safe, timely, patient-centered, efficient, effective, and equitable.

To meet this definition, it is essential to pursue objectives of improving quality, reducing medical errors, and decreasing costs by eliminating all forms of waste, based on the four areas into which quality can be split, ie, technical quality, efficiency, risk management, and patient satisfaction. ${ }^{37}$ However, these aspects should be adapted to a process-based perspective (eg, considering process efficiency instead of efficiency in use of resources). Therefore, based on the definition of quality used by the World Health Organization $^{34}$ and shared by the Agency for Healthcare Research and Quality and Institute of Medicine, ${ }^{35,36}$ which seems the most comprehensive so far, adequate managerial methodologies should be developed in health care to achieve effectiveness, efficiency, patient-centered organization, and safety at the same time.

\section{Recent developments in managerial approaches to improve performance}

Managerial approaches derived from the industrial context, such as health care lean management (HLM) and clinical risk management (CRM), could help to ensure the quality attributes mentioned above, but a single approach may not be sufficient to guarantee them all. Following the definition used by Walshe and Dineen, ${ }^{38}$ CRM is: “ $\ldots$ an approach to improve quality in health care which places special emphasis on identifying circumstances which put patients at risk of harm, and then acting to prevent or control those risks. The aim is to both improve safety and quality of care for patients and to reduce the costs of such risks for healthcare providers." Therefore, it seems that inadequate management of quality and patient safety leads to an increase in costs. The need to adopt CRM is also born from the crisis that happened in the insurance market, resulting in substantial increases in insurance premiums, which forced the need to adopt different techniques to manage clinical risk. ${ }^{39}$

Clinical risk, defined as the "dark side of quality", ${ }^{40}$ therefore has an impact on the level of costs if not properly managed. To achieve this error reduction, ie, ensure greater patient safety, several basic CRM tools have been used, ${ }^{41-47}$ ie, risk identification, risk evaluation, risk treatment, and risk monitoring. ${ }^{48,49}$

Following the logic proposed by Ferdows and De Meyer, ${ }^{21}$ quality and patient safety have to form the base of the sand cone in health care, ie, they have to be guaranteed first, consequently avoiding a negative impact on efficiency performance.

Stuart ${ }^{50}$ highlighted, as did Taguchi, the definition of quality loss function in the industrial sector. Non-quality costs included were repairs, assistance service, waste, and warranty; moreover, Stuart verified that the amount of losses is proportional to the square of performance deviation from the target. Cosmin and Stanciuc ${ }^{51}$ also considered the costs supported to ensure high levels of quality in the previous relationship. It can be expected that even in health care these relationships could be verified, given the parallel that is barely visible in at least some types of costs (eg, waste and assistance), in the costs of bad quality, and those related to preventive health care, highlighted in several studies. ${ }^{52,53}$ In CRM, prevention activities with double-checks 
and duplications are often carried out, even if they are not always necessary.

In the health sector, industrial instruments and techniques of quality management have being adopted for quality improvement, as reported in the academic and management literature over the last 20 years. Among them are PDCA (Plan, Do, Check, Act), quality function deployment, International Organization for Standardization 9000, total quality management, business process re-engineering, Lean Six Sigma, quality control, quality assurance, quality function deployment, and lean thinking. ${ }^{54-61}$ In recent years, the use of tools for lean management, for example, has been increasing, inspired by the "Henry Ford production system." $62-64$

Despite implementation of these different practices, errors reported in health care are still unacceptable and related costs still show a positive trend, as shown by data from the Organization for Economic Cooperation and Development. ${ }^{65}$

Starting from the definitions provided, overlaps and possible integration between the approaches of CRM and HLM emerge, connecting the concepts of added value and perfection present in lean principles (ie, precisely specify value, identify the value stream, make value flow without interruptions, pull approach, pursue perfection), ${ }^{66}$ to the definition of quality used and required at the international level (World Health Organization). On the other side, CRM, through the tools and practices it provides, allows pursuit of perfection, error reduction, and greater efficiency.

Therefore, there is a two-way arrow connecting CRM and HLM: not only is quality the necessary basis for ensuring cost reduction, but HLM, as a business management strategy encompassing a set of principles, practices, and methods for designing, analyzing, and managing processes, ${ }^{55}$ could support the detection of high-risk situations. In fact, considering Reason ${ }^{67}$ and Kohn et al, ${ }^{68}$ reliable systems can develop only if the culture of blame is abandoned and the right barriers, in terms of procedures, protocols, and process control, are erected.

HLM supporting CRM is further confirmed by the following definition of HLM. ${ }^{66,69}$ HLM is a managerial approach to identify and eliminate waste, while improving flow of activities to maximize customer value; it considers specification and standardization of work processes, organization of work in such a way that unexpected events are easy to spot, and deployment of activities that find and fix mistakes.

A recent literature review ${ }^{70}$ analyzed the links and overlaps between CRM and HLM. From this study, it emerged that the two approaches are implemented separately and alternatively, without following an integrated view. Moreover, the authors identified that there are no studies focusing on the relationship between HLM and CRM. Notwithstanding this, in HLM papers, some partial objectives of CRM are pursued and some CRM methodologies are adopted, but not all the phases of the CRM process are considered.

Some empirical cases have achieved quality improvement and patient satisfaction, reducing waste and cutting costs. ${ }^{71,72}$ However, other studies have shown that the measures of quality in health care are not appropriate, and little attention is devoted to other aspects, such as the impact of such approaches on employees, ${ }^{64,73}$ while the advantages in terms of cost and efficiency improvement are evident. ${ }^{64,74,75}$

Some indications emerge from the cases examined; in particular, this approach should be adopted after providing the right education and training to both employees and management, given that if a real commitment from top management is lacking, it is unlikely that implementation of these practices will be successful. In addition, this approach should introduce a shared culture across the entire organization; it should not be adopted in some selected hospital units, because this may lead to creation of islands of excellence and achievement of local targets only. Successful implementation requires a detailed vision of the process, which involves different departments and different areas, depending on the health care process concerned.

\section{Opportunities for future research}

Two future research streams emerge from the previous considerations, the first of which concerns quality approaches and the measurement system. The following aspects should be investigated in more detail:

- quality of care should be defined in an unambiguous and shared way, considering the different points of view discussed above, and the characteristics defining quality should be usable both in adopting a system view or referring to the processes view

- research should be conducted to define quality measures allowing to evaluate and control the achievement of high quality

- replication and adaptation of the sand cone theory could be studied, identifying the strategies that contribute to obtaining high quality levels

- new managerial tools and practices, drawn in particular from HLM and CRM, should be adopted to measure, control, and improve quality in each of the components (see Figure 1). 


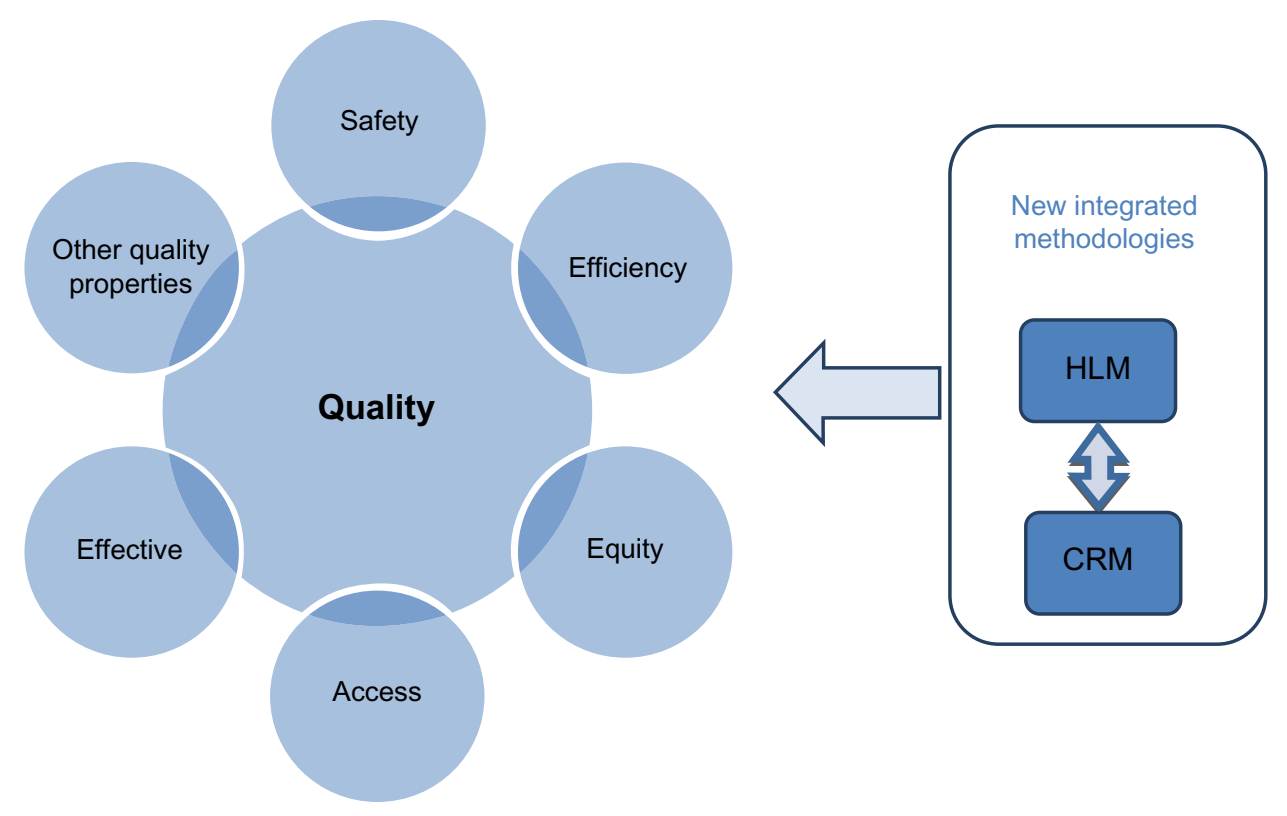

Figure I Quality definition and impacts of new managerial approaches on quality performance. Abbreviations: HLM, health care lean management; CRM, clinical risk management.

Considering the multiplicity of objectives, a second research stream concerns the opportunity to develop methodologies that integrate different managerial approaches in order to gain advantages from each of them. In particular, future research could focus on the development of an integrated methodology to manage clinical processes, exploiting the synergies between HLM and CRM. This stream entails the following:

- comparing lean management project phases with the CRM process to analyze the overlaps and links between them

- investigating comparatively the main managerial tools, practices, and guidelines adopted in HLM and CRM

- identifying projects with both HLM and CRM evidence as "safety and lean projects"; theoretical and empirical research should be undertaken in order to provide guidelines to succeed in the implementation of these projects; the possibility to build a synergic process to manage "safety and lean projects" has never been considered in the literature

- the hypothesized new integrated managerial approach will probably need new professionals, sometimes called "T-men," ${ }^{76}$ who are able to integrate knowledge, management systems, and people; this appears to be confirmed by the presence of personnel with engineering and management capabilities in the first lean management projects with safety fallout.

Regarding the key factors for successful implementation of "lean and safety projects", first indications could be grasped from studies in the two different research streams. In the industrial sector, Shah and Ward ${ }^{77,78}$ have highlighted the need to consider "soft" aspects in addition to the "hard" ones. Lean production is defined by Shah and Ward ${ }^{77}$ as an integrated sociotechnical system that should not neglect the social dimension during its implementation. Given that lean is a philosophy, guidelines should be followed to create a lean culture. ${ }^{79-81}$

Many of the guidelines recommended for successful implementation of lean management projects are not so far from the ones highlighted by authors studying CRM. ${ }^{48,82}$ Moreover, Cagliano et al ${ }^{83}$ give an example of early incomplete research that tried to combine some aspects of CRM with lean techniques.

The chance to develop these new research streams thus seems reasonable and reveals interesting opportunities to extend current knowledge in the academic health care literature. Further developments will contribute to finding successful solutions to overcoming health care challenges, achieving the multiple objectives of health care companies and evolving through a better society.

\section{Disclosure}

The authors report no conflicts of interest in this work.

\section{References}

1. Stuckler D, Basu S, McKee M, Suhrcke M. Responding to the economic crisis: a primer for public health professionals. J Public Health (Oxf). 2010;32:298-306. 
2. Donahue KT, Vanostenberg P. Joint Commission International accreditation: relationship to four models of evaluation. Int J Qual Health Care. 2000;12:243-246.

3. World Health Organization. The Ljubljana Charter on Reforming Health Care. Ljubljana, Slovenia: European Member States; 1996. Available from: http://www.euro.who.int/en/publications/policy-documents/ the-ljubljana-charter-on-reforming-health-care,-1996. Accessed October 14, 2013.

4. World Health Organization. Regional office for Europe. HEALTH $21-$ health for all in the 21 st century. Geneva, Switzerland: World Health Organization; 1998. Available from: http:/www.euro.who.int/en/ publications/policy-documents/health21-health-for-all-in-the-21stcentury. Accessed October 14, 2013.

5. Ministry of Health, Department of Programming. Quality and National Health Service: References and Documentation. 1999.

6. Parasuraman A, Zeithaml VA, Berry LL. A conceptual model of service quality and its implications for future research. J Mark. 1985;49:41-50.

7. Bateson JE, Hoffman KD. Managing Service Marketing. New York, NY: The Dryden Press, Harcourt Brace College Publishers; 1999.

8. Cicchetti A. L'Organizzazione dell'Ospedale. [The Hospital Organization.] Milan, Italy: Vita e Pensiero; 2002.

9. Shortell SM, Kaluzny AD. Health Care Management: Organization, Design, and Behavior. New York, NY: Delmar; 1994.

10. Bruzzi S. La Gestione dell'azienda Sanitaria: Innovazione e Scelte Strategiche per un Nuovo Scenario Competitivo. [The Management of Health care Organization: Innovation and Strategic Choices for a New Competitive Scenario.] Milan, Italy: Giuffrè Editore; 2006.

11. Serpelloni G, Simeoni E. Quality Management. Verona, Italy: La Grafica; 2002.

12. Skinner W. Manufacturing: The Formidable Competitive Weapon. New York, NY: John Wiley; 1985.

13. Hayes RH, Wheelwright SC. Restoring Our Competitive Edge: Competing Through Manufacturing. New York, NY: John Wiley; 1984.

14. Noble MA. Manufacturing strategy: testing the cumulative model in a multiple country context. Decision Sciences. 1995;26:693-721.

15. Lapré MA, Scudder GD. Performance improvement paths in the US airline industry: linking trade-offs to asset frontiers. Production and Operations Management. 2004;13:123-134.

16. Schmenner RW, Swink ML. On theory in operations management. Journal of Operations Management. 1998;17:97-113.

17. Da Silveira G, Slack N. Exploring the trade-off concept. International Journal of Operations and Production Management. 2001;21: 949-964.

18. Mapes J, New C, Szwejczewski M. Performance trade-offs in manufacturing plants. International Journal of Operations and Production Management. 1997; 17:1020-1033.

19. Hayes RH, Pisano GP. Manufacturing strategy: at the intersection of two paradigm shifts. Production and Operations Management. 1996;5:25-41.

20. Boyer KK, Lewis MW. Competitive priorities: investigating the need for trade-offs in operations strategy. Production and Operations Management. 2002;11:9-20.

21. Ferdows K, De Meyer A. Lasting improvements in manufacturing performance: in search of a new theory. Journal of Operations Management. 1990;9:168-184.

22. Takala J, Leskinen J, Sivusuo H, Hirvelä J, Kekäle T. The sand cone model: illustrating multi-focused strategies. Management Decision. 2006; $44: 335-345$

23. Lewis RC, Booms BH. The marketing aspects of service quality. In: Berry L, Shostack L, Upah G, editors. Emerging Perspectives on Services Marketing. Chicago, IL: American Marketing Association; 1983.

24. Bitner MJ, Hubbert AR. Encounter satisfaction versus overall satisfaction versus quality: the customer's voice. In: Oliver RT, Rust RL, editors. Service Quality: New Directions in Theory and Practice. Thousand Oaks, CA: Sage Publications; 1994.
25. Taylor SA, Cronin JJ. Modeling patient satisfaction and service quality. J Health Care Mark. 1994;14:34-44.

26. Andaleeb SS. Service quality perceptions and patient satisfaction: a study of hospitals in a developing country. Soc Sci Med. 2001;52: 1359-1370.

27. Laffel G, Blumenthal D. The case for using industrial quality management science in health care organizations. JAMA. 1989;262:2869-2873.

28. Lohr KN, Donaldson MS, Harris-Wehling J. Medicare: a strategy for quality assurance. V. Quality of care in a changing health care environment. QRB Qual Rev Bull. 1992;18:120-126.

29. Active Citizenship Network. European Charter of Patients'Rights. Brussels, Belgium; Active Citizenship Network; 2002.

30. General Assembly Resolution. Universal declaration of human rights. Resolution adopted by the General Assembly, 10.12.1948. Available from: http://www.un.org/en/documents/udhr/history.shtml. Accessed October 14, 2013

31. Agency for Healthcare Research and Quality. Testimony on Health Care Quality. 2013. Available from: http://www.ahrq.gov/news/newsroom/ speech/index.html. Accessed October 14, 2013

32. Buttell P, Hendler R, Daley J. Quality in Healthcare: Concepts and Practice. The Business of Healthcare. Westport, CT: Praeger; 2008.

33. Holbrook MB, Corfman KP. Quality and value in the consumption experience: Phaldrus rides again. In: Jacoby J, Olson J, editors. Perceived Quality. Lexington, MA: Lexington Books; 1985.

34. World Health Organization. Quality of care: a process for making strategic choices in health systems. WHO Regional Office for the Western Pacific; 2006. Available from: http://www.who.int/management/quality/ assurance/QualityCare_B.Def.pdf. Accessed October 14, 2013.

35. Agency for Healthcare Research and Quality. National health care disparities report, 2011. Available from: http://www.ahrq.gov/research/ findings/nhqrdr/nhqr11/nhqr11.pdf. Accessed October 14, 2013.

36. Institute of Medicine. Crossing the Quality Chasm: A New Health System for the 21st Century. Washington, DC: National Academy Press; 2001.

37. World Health Organization. The Principles of Quality Assurance. Copenhagen, Denmark: World Health Organization; 1983. Available from: http://whqlibdoc.who.int/euro/r\&s/EURO_R\&S_94.pdf. Accessed October 14, 2013

38. Walshe K, Dineen M. Clinical Risk Management. Making a Difference? Birmingham, UK: The NHS Confederation, University of Birmingham; 1998.

39. Misani N. [Introduction to Risk Management]. Milan, Italy: EGEA; 1994. Italian.

40. Vincent C. Risk, safety and the dark side of quality. BMJ. 1997;314: 1775-1776.

41. Walker JS, Wilson M. Clinical risk management in anaesthesia. Qual Health Care. 1995;4:115-121.

42. Pradhan M, Edmonds M, Runciman WB. Quality in healthcare: process. Best Pract Res Clin Anaesthesiol. 2001;15:555-571.

43. Kavaler F, Spiegel AD. Risk Management in Health Care Institutions. A Strategic Approach. Sudbury, MA: Jones and Bartlett Publishers; 2003.

44. Chang A, Schyve PM, Croteau RJ, O'Leary DS, Loeb JM. The JCAHO patient safety event taxonomy: a standardized terminology and classification schema for near misses and adverse events. Int J Qual Health Care. 2005;17:95-105.

45. Kumar S, Steinebach M. Eliminating US hospital medical errors. Int J Health Care Qual Assur. 2008;21:444-471.

46. Bhutani VK, Johnson L. A proposal to prevent severe neonatal hyperbilirubinemia and kernicterus. J Perinatol. 2009;29:S61-S67.

47. Trucco P, Cavallin M. A quantitative approach to clinical risk assessment: the CREA method. Saf Sci. 2006;44:491-513.

48. Verbano C, Turra F. A human factors and reliability approach to clinical risk management: evidence from Italian cases. Saf Sci. 2010;48: 625-639.

49. Verbano C, Venturini K. Development paths of risk management: approaches, methods and fields of applications. J Risk Res. 2001;14: 519-550. 
50. Stuart G. Taguchi Methods: A Hands-on Approach. New York, NY: Addison Wesley; 1993.

51. Cosmin D, Stanciuc AM. Cost of quality and Taguchi loss function. Annals of Faculty of Economics. 2013;1:1479-1485.

52. Øvretveit J, Tolf S. The costs of poor quality and adverse events in health care - A review of research for the Swedish healthcare compensation insurance company. Stockholm, Sweden: The Medical Management Centre, The Karolinska Institutet; 2009. Available from: http://www.patientforsakring.se/resurser/dokument/patientsakerhet/_ OvretTolfCostAEsafety9Oct09.pdf. Accessed October 14, 2013.

53. Varkey P, Kollengode A. A framework for healthcare quality improvement in India: the time is here and now! J Postgrad Med. 2011;57: 237-241.

54. Radnor ZJ, Holweg M, Waring J. Lean in healthcare: the unfilled promise? Soc Sci Med. 2012;74:364-371.

55. Schweikhart SA, Dembe AE. The applicability of lean and six sigma techniques to clinical and translational research. $J$ Investig Med. 2009;57:748-755.

56. Varkey PK, Reller M, Resar RK. Basics of quality improvement in health care. Mayo Clinic Proc. 2006;82:735-739.

57. Kruskal JB, Reedy A, Pascal L, Rosen MP, Boiselle PM. Quality initiatives: lean approach to improving performance and efficiency in a radiology department. Radiographics. 2012;32:573-587.

58. Joint Commission on Accreditation of Healthcare. Facts about the Joint Commission. 2006. Available from: http://www.jointcommission. org/assets/1/18/Facts_The_Joint_Commission.pdf. Accessed October 14, 2013.

59. Bertolaccini L, Rizzardi G, Filice MJ, Terzi A. Six Sigma approach an objective strategy in digital assessment of postoperative air leaks: a prospective randomised study. Eur J Cardiothorac Surg. 2011;39: e128-e132.

60. Feng Q, Manuel CM. Under the knife: a national survey of six sigma programs in US healthcare organizations. Int J Health Care Qual Assur. 2008;21:535-547.

61. Harrington H, Trusko B. Six Sigma: an aspirin for health care. Int $J$ Health Care Qual Assur. 2005;18:487-515.

62. De Souza LB. Trends and approaches in lean health care. Leadersh Health Serv (Bradf Engl). 2009;22:121-139.

63. Laursen M, Gertsen F, Johanson J. Applying Lean Thinking in Hospitals - Exploring Implementation Difficulties. Aalborg, Denmark: Center for Industrial Production, Aalborg University; 2003.

64. Mazzocato P, Savage G, Brommels M, et al. Lean thinking in healthcare: a realist review of the literature. Qual Saf Health Care. 2010;19: 376-382.

65. Organisation for Economic Cooperation and Development. Health at a Glance: Europe 2012. Available from: http://www.oecd.org/health/ healthataglanceeurope.htm. Accessed October 14, 2013.
66. Womack JP, Jones DT. Lean Thinking - Banish Waste and Create Wealth in your Corporation. New York, NY: Free Press; 2003.

67. Reason JT. Human error: models and management. BMJ. 2000;320: 768-770.

68. Kohn LT, Corrigan J, Donaldson MS. To Err Is Human: Building a Safer Health System. Washington, DC: National Academies Press; 2000.

69. Ohno T. Toyota Production System, Beyond Large-Scale Production. Boca Raton, FL: Productivity Press; 1988.

70. Crema M, Verbano C. Health lean management and clinical risk management: a systematic literature review. Proceedings of the 6th Annual EuroMed Conference. Confronting Contemporary Business Challenges through Management Innovation. Lisbon, Portugal, September 23-24, 2013.

71. Printezis A, Gopalakrishnan M. Current pulse: can a production system reduce medical errors in health care? Qual Manag Health Care. 2007;16:226-238.

72. Biffl WL, Beno M, Goodman P, et al. Leaning the process of venous thromboembolism prophylaxis. Jt Comm J Qual Patient Saf. 2011;37: 99-109.

73. Holden RJ. Lean thinking in emergency departments: a critical review. Ann Emerg Med. 2011;57:265-278.

74. Sunyog M. Lean management and Six-Sigma yield big gains in hospital's immediate response laboratory. Quality improvement techniques save more than \$400,000. Clin Leadersh Manag Rev. 2004;18: 255-258.

75. Vats A, Goin M, Villarreal T, et al. The impact of a lean rounding process in a pediatric intensive care unit. Crit Care Med. 2012;40:608-617.

76. Petroni G, Venturini K, Verbano C. Open innovation and new issues in R\&D organization and personnel management. The International Journal of Human Resource Management. 2012;23:147-173.

77. Shah R, Ward PT. Defining and developing measures of lean production. Journal of Operations Management. 2007;25:785-805.

78. Shah R, Ward PT. Lean manufacturing: context, practice bundles, and performance. Journal of Operations Management. 2003;21:129-149.

79. Dahlgaard JJ, Dahlgaard-Park SM. Lean production, Six Sigma quality, TQM and company culture. The TQM Magazine. 2006;18:263-281.

80. Bhasin S, Burcher P. Lean viewed as a philosophy. Journal of Manufacturing Technology Management. 2006;17:56-72.

81. Mann D. Creating a Lean Culture: Tools to Sustain Lean Conversions. Boca Raton, FL: CRC Press; 2012.

82. Dal Corso L, De Carlo NA, Salmaso L. Risk management, quality and safety in healthcare. In: De Carlo NA, Faa G, Rutelli P. Humanization and Health Occupation. Communication, Organisation and Territory. Milan, Italy: Franco Angeli; 2008.

83. Cagliano A, Grimaldi S, Rafele C. A systemic methodology for risk management in healthcare sector. Saf Sci. 2011;49:695-708.
Journal of Multidisciplinary Healthcare

\section{Publish your work in this journal}

The Journal of Multidisciplinary Healthcare is an international, peerreviewed open-access journal that aims to represent and publish research in healthcare areas delivered by practitioners of different disciplines. This includes studies and reviews conducted by multidisciplinary teams as well as research which evaluates the results or conduct of such teams or health-

\section{Dovepress}

care processes in general. The journal covers a wide range of areas and welcomes submission from practitioners at all levels, from all over the world. The manuscript management system is completely online and includes a very quick and fair peer-review system. Visit http://www.dovepress com/testimonials.php to read real quotes from published authors. 